\title{
Comparative Analysis of Health Care Delivery System: Pakistan vs. Brunei Darussalam
}

\author{
Muhammad Younas ${ }^{1}$, Misbah Zafar ${ }^{2}$ \\ mys.khan1[at]yahoo.com ${ }^{1}$, amenmisbah99[at]gmail.com ${ }^{2}$ \\ ${ }^{1}$ Clinical Nurse Manager at Shaukat Khanum Memorial Cancer Hospital Peshawar, Pakistan \\ ${ }^{2}$ Saida Waheed FMH College of Nursing, Lahore Pakistan \\ Corresponding Author \\ Email: mys.khan1[at]yahoo.com \\ Contact: +923456100856 \\ Postal Address: Village and P.O Ghalegay Tehsil and District Swat Khyber Pakhtunkhwa, Pakistan
}

\begin{abstract}
Health of a nation depends upon the healthcare system of their country, and a country health policy is the backbone of its healthcare system. To attain economic stability, a country must have a better and effective healthcare delivery system which will produce a good labor force. Many developing countries are reforming their healthcare systems to meet the ongoing challenges in demographics and to overcome the increasing burden of chronic and non-communicable disease. Pakistan is administratively composed of four provinces; Sindh, Punjab, Baluchistan, Khyber Pakhtunkhwa (KP) and along with it federally administered tribal areas (FATA) and Gilgit Baltistan (GB) region. This paper focuses on comparative analysis of healthcare delivery system of Pakistan and Brunei. Brunei Darussalam is a small country in South-East Asia. Unlike Pakistan it has four districts; Brunei-Muara, Tutong, Belait and Temburong. Climate is tropical, with high humidity and heavy rainfall with sudden thundery showers in the months of January and November only.
\end{abstract}

Keywords: Health Care System, comparative analysis, Pakistan vs Brunei, Public health

\section{Significance for Public Health}

The topic is of very much significance to public health, as a country's health care system portrays the health of the natives. The achievement of Millennium Developmental Goals is only possible through an effective health care system. It has become a recognized priority that the achievement of major public health goals (like initiative for HIV/AIDS, tuberculosis, malaria, childhood immunizations, and others) is only possible by strengthening the health care system (1). A country's health policy and effective health care system affects the health of people at the healthcare organizations as well as in the communities.

\section{Health status of Pakistan and Brunei}

The population of Pakistan is 188 million making it the sixth largest populous country in the world, and by the year 2050 the population of Pakistan will become double fold (363 million) while the rank will still remain the same i.e. sixth position (2). The growing population is making a big challenge to provide basic health services to the population. The high population growth rate of Pakistan (1.95 percent) due to its high fertility rate, places it on the top among the average population growth of South Asian countries (2). The maternal mortality rate (MMR) of Pakistan is 276 maternal deaths per 100,000 live births and neonate mortality (NMR) is 55 deaths per 1,000 live births and a significant prevalence of HIV/AIDS (3).

Comparing to Pakistan Brunei is a small country; according to 2012 census the total population of Brunei Darussalam is 412,000. In 2012 the life expectancy in
Brunei Darussalam for male is $78.5 \mathrm{y}$ and for female is $79.3 \mathrm{y}$. The population growth rates between the years of 1990 and 2012 rest at 2.1 per cent p.a. (4).

\section{Healthcare delivery system of Pakistan and Brunei}

In June 2011 as part of the $18^{\text {th }}$ constitutional amendment, health became the major responsibility of provincial government except for the federal administered tribal areas. Whereas national health policy and regulation, interprovincial synchronization, health information comes under the federal government (5). Pakistan health care system comprises of both public and private sector. Health is delivered as primary, secondary and tertiary care. The primary care is provided through basic health units (BHUs) and rural health centers (RHCs). The care at secondary level and inpatients are dealt in District Headquarter Hospitals (DHQs) and Tehsil Headquarter Hospitals (THQs) and teaching hospitals (tertiary care hospitals) are committed to tertiary care. The private sector includes private hospitals, private clinics, homeopaths, Hakeem's (Muslims physicians), bonesetters and folk healers. The private sector is the main providers of health services and covers 60 to 70 percent of health care services in Pakistan (6).

In Brunei Darussalam for a healthy nation principle and approach, healthcare based on the curative, preventive and promotive universal health care coverage and emphasis on the primary health care. The healthcare delivery system of Brunei is simple as it is a very small country comparing to Pakistan. Since 1984 to date there are 4 Government hospitals in each district (968 beds) and 2 Private 


\section{International Journal of Science and Research (IJSR) \\ ISSN (Online): 2319-7064}

Index Copernicus Value (2016): 79.57 | Impact Factor (2015): 6.391

Hospitals in the capital district (Bander Seri Begawan) are working in Brunei Darussalam. In Pakistan for a population of 188 million, 0.6 percent of the GDP is allocated for health which shows a low priority for health. Public sector covers only 33.3 percent of health expenditure while the private provides 59.8 percent which is the largest portion. Within the private sector 57.3 percent is out of pocket payments, private employee accounts for 1.6 percent and philanthropy accounts for 0.9 percent. Besides this, semi-government agencies provide 5.1 percent and 1.7 percent consists of donor and NonGovernment Organization (NGO) assistance (6). On the other hand the government of Brunei Darussalam spends $2.5 \%$ of GDP for its population of 412,000 every year for health expenditure (4). This shows the importance and priority of Brunei's government for health. In addition health care in Brunei is fully subsidized by the government for the local citizens. The petroleum, natural gas industry and armed forces have their own Occupational Health Services. Moreover the country imports a good number of its pharmaceutical requirements from the wealth of raw materials provided by the country's rainforests, which provide halal pharmaceutical market (4). In addition, there is no concept of family planning in Brunei Darussalam. However they are not against of these services as well.

\section{Goals and Expectations of Pakistan and Brunei}

Pakistan healthcare system has evolved from the era of British Empire, in an undeveloped condition and the condition still remains deprived. Goal of the national health policy is that every Pakistani should have access to affordable essential healthcare services without any barriers (7). Some of the essential health indicator like Neonatal mortality rate (NMR) in 1990-91 was estimated at 51 deaths per 1,000 live births, and during the past five years it has increased to 55 deaths per 1,000 live births. The goal for MMR was set to reduce it to 140 maternal deaths per 1,000 live births while the current figure is 276 maternal deaths per 100,000 live births (3). With such a significant increase in the health indicators attainment of Millennium Development Goals (MDGs) 4, 5 and 6 by the year 2015 does not seem promising. In addition the attainment of (MDGs) 1, 2, 3 is also not possible which aims to eradicate extreme poverty and hunger, achievement of universal primary education and promoting women empowerment and gender equality respectively (3). Besides this, Pakistan has also failed in polio eradication among most the developing countries. In 2014 about 104 cases are reported all over from Pakistan with majority of cases from (FATA) (8).

On the other hand Brunei Darussalam is working to accomplish the MDG 4 for the reduction of child mortality and increase measles immunization to 100 per cent by 2015 (9). The global MDG 5 objective for maternal health is to decrease the number of pregnant women by three quarters between 1990 and 2015 (9). MDG 6 goal to decrease the prevalence of HIV and malaria or Polio; consequently unlike Pakistan, malaria and Polio has already been eradicated in country since 1987 and 2000 respectively. However, inadequate data is available to confirm the country's progress on HIV/AIDS. In addition, estimated TB incidences have remained roughly the same since 1990 therefore essential improvements are needed to target TB prevention and enhance treatment. In this regard DOTS program is working efficiently with the Brunei Darussalam to control over the TB (9). All health care workers timely immunized and vaccinated for Hepatitis A, $\mathrm{B}, \mathrm{C}$ or any epidemic diseases around the world.

\section{Resources Pakistan and Brunei}

Pakistan is a developing country and the health system is in deprived condition in terms of resources. Lack of proper resources and lack of proper utilization of resources contributes to the deprived condition of health system in Pakistan. The overall health facility in terms of manpower includes 167,759 registered doctors, 86,183 registered nurses, 13,716 registered dentists. The total number of hospitals have increased to 1096, basic health units (BHUs) are more than 5527, rural health centers (RHCs) 650 and the number of dispensaries is 5310 (2). In addition there are also 288 Tuberculosis Centers and 905 Maternal and Child Health (MCH) Centers (10). There is a need of proper check and balance, supervision and accountability system for proper utilization of health care workers force. Health management information system is not considered an essential field. Promotions are offered on seniority basis which should be merit based in order to bring quality. Absenteeism of doctors and other healthcare providers is yet another chronic problem of Pakistan's healthcare system.

In contrast Brunei Darussalam is a well-equipped and stable country. The Raja Isteri Pengiran Anak Saleha (RIPAS) Hospital is the largest and referral hospital of the country with more than 600 beds. Hospital is fully equipped with modern health care technology and facilities. There is a 24 hours health shuttle service (by road, by water and by air) for the referral patients from other districts hospitals to RIPAS hospital in case of special care services. In respect of holistic approach Muslim patients can have the accessibility of religious leaders, which they usually called USTAZ, who are regular hospital employee and are available 24 hours within the hospital premises. In addition, 17 Health Centers, 9 Medical Clinics (Ministry of Defense), 12 Maternal \& Child Health Clinics, 39 dental Clinics, 3 Travelling Clinics, 4 Flying Medical Services and 6 Dialysis Centers are working side by side for the welfare of the nation on free of cost for the local residences. In addition, good triage with nonstop ER services is available 24 hours for the care of patients. All over the Brunei including public and private hospitals population per doctor 647 with total number of 608 , population per nurse 8,191 with total number of 2,628 , population per dentist 4,139 with total number of 95 and population per pharmacist 8,191 with total number of 48 existed (11).

This shows that the health resources of Brunei Darussalam are sufficient for its population comparing to Pakistan where the resources are not adequate.

\section{Volume 6 Issue 12, December 2017}




\section{International Journal of Science and Research (IJSR)}

ISSN (Online): 2319-7064

Index Copernicus Value (2016): 79.57 | Impact Factor (2015): 6.391

\section{Technology domain of Pakistan and Brunei Darussalam}

In today's modern era technology has improved our lives that life of ordinary people is not possible without technology. Same improvement is needed in the field of health for diagnostic and interventions and treatment purposes. Pakistan lags behind in terms of technology specifically the public sector. The condition is even worsening in rural areas, where even the available technology is sometime not in proper working condition and people are compelled to pay heavy fees out of their pocket at private sector. Pakistan lacks the technological advancement like, E-health, Telemedicine, real time videoconferencing this is one of the reasons that health care system in Pakistan is still below the standard line.

On the contrary Brunei Darussalam is a small country but well equipped in its domain of technology. Brunei health care system is fully equipped with modern technology and skilled workers from national and international resources. They have well modernized computed tomography (CT) \& magnetic resonance imaging (MRI) scan equipment. Recently, they introduced HMIS which meets all the modern requirements of health care facility to all four district hospitals, health centers and clinics across the country to see every patient in Brunei with a single electronic health record, making the "One Patient, One Record" journey a reality (11).

Authority, Power and Status structure/Decision Making Process of Pakistan and Brunei Darussalam

After the devolution plan of $18^{\text {th }}$ constitutional amendment health in Pakistan is now provincial matter. Healthcare in Pakistan works as vertically and horizontally. In the vertical system the organizations works independently such as, provincial health departments, armed forces, NGOs and private health sector. In addition the horizontal system comprised of the federal ministry of health and national health programs which run across the country (12). The federal government works at policy level, strategic planning and international coordination. On the other hand provincial government is responsible for delivering health care to the consumers. At provincial level secretary health is the higher authority for important health related decision making. Director General Health (DG) is second in hierarchy and is responsible for regulating the manpower under BPS 16. Then the District Health Officer (DHO) looks the maters at district level e.g. BHUs, RHCs and polio campaigns and tuberculosis (TB) and malaria program. The medical superintendent (MS) is responsible for controlling and regulating (DHQs) related matters. The overall health status in Pakistan is poor. There is a lack of coordination and collaboration among the health departments. There is no tradition of proper check and balance, accreditation and quality assurance. Almost 70 percent of the healthcare services are provided by the private sector.

Pakistan now becomes the only country without central ministry of health. The provincial autonomy however can help in retaining the health goals (5). Almost all of the vertical health programs have been handed over to provinces except few such as malaria, AIDS and TB programs. All of the provinces run their own healthcare systems; and forms strategic planning and healthcare decision autonomously with the support of federal government for programs implementation. Hospital level decisions like, material supply, staff recruitment is done at provincial level which the district level can handle effectively. A proper and adequate evidence, statistics and facts and figures are required for proper effective planning and decision which unfortunately Pakistan healthcare system lacks.

In contrast, the authority, power and status structure of Brunei very much effective and simple. In Brunei the focal authoritative person of health care system is the Sultan of Brunei. However, officially distribution of the authorities starts with the $\mathrm{MOH}$ and a permanent secretary. Following this there are two deputy permanent secretaries, one is responsible for professional and the second is responsible for administration and finance matters. The general director works under deputy permanent secretaries and is responsible for; policy and planning, technology services, estate management and health promotion centers. There are one director-general (DG) of medical services and one DG health services who works under the general director. The DG medical services is responsible for; hospital services, nursing services, pharmaceutical services, laboratory services, dental services and renal services. The DG health services, is responsible for community health services, scientific services and environmental health services. For the Ministry of health organizational chart please refer to Appendix A.

\section{Primary problems/challenges of Pakistan}

Pakistan healthcare system is suffering from multiple problems. First and foremost problem starts with the incompetent government and administrative bodies, the authoritative political system, and the bureaucratic civil system. There is corruption; no tradition of merit, selection is based on preferences and political influences. Promotion of staff is based on number of years of working rather than ability and performance. There is lack of unanimous evidence, statistics and facts and figures. Low allocation of budget shows low priority for health. Some of the challenges include; inadequate infrastructure, inadequate staffing and lack of proper check and balance. There is lack of public private partnership despite the 70 percent services are provided by the private sector only. Lack of proper disposal of waste and biohazards is an ongoing source of infection and pollution. The healthcare professionals in general and specifically nurses are prone to harassment of all type on daily basis. The brutal killing of polio workers and LHWs proves the level of insecurity.

\section{Primary problems and challenges of Brunei}

On the contrary the health care system of Brunei is very much effective; comparing to Pakistan it has minimal problems. However, it faces some health related 


\section{International Journal of Science and Research (IJSR) \\ ISSN (Online): 2319-7064}

Index Copernicus Value (2016): 79.57 | Impact Factor (2015): 6.391

challenges. The challenges faced by the Brunei healthcare system are of Non Communicable Diseases in shape of people's life style, dietary pattern, ageing population, heart disease, diabetes, cerebrovascular and obesity. From 1997 to 2011 loverweight and obesity trend can be seen widely in Brunei Population (13). Moreover overweight and obesity for school going children especially in year $1,4,6$, and 8 is extremely high from 2008-2010 (13). The second most common Non Communicable Diseases in Brunei are cardiovascular diseases. In addition, cancers, diabetes and respiratory diseases contributed 16 per cent, 11 per cent and eight per cent to total mortality respectively (11). Prevalence of tuberculosis has seen a very minor increase in the year 1990-2012. Three cases of leprosy were reported in 2010 and 49 people HIV cases were declared in 2011(4). In mental health the most commonly diagnosed mental illnesses are depression, personality disorder and anxiety (4). Due to prohibition of alcohol, psychiatric disorders related to alcohol use are uncommon or unheard. All these cases are very much treating in the RIPAS hospital following full protocols. In Brunei there is no medical college at national level. All their local doctors are trained mostly from UK. In addition future challenges for Brunei government in the health care sector as per increasing public expectations could be;

\section{Conclusion}

In conclusion Brunei is a very small country as compared to Pakistan. However, the health care system of Brunei is better than that of Pakistan in terms of delivery system, goals, responsibilities, decision and authorities. In addition, unlike Pakistan the sufficient amount of budget specified by Brunei for its healthcare system proves their importance for health and their commitment to provide a safe and healthy living for their nation.

\section{Recommendations for Problems / Challenge Resolution}

We suggest the following recommendations for the Pakistani healthcare delivery system.

- Appointment and promotion of employments should only on merit basis.

- Reinforcement of legislation to minimize political influence and corruption.

- Adequate allocation of budget for health.

- Effective audit and check and balance system to identify the loop holes.

- Secure and harassment free healthcare environment.

- A proper health information management (HIMS).

- Stress on evidence based practices and research activities.

- Proper disposal of waste and biohazards to minimize the sources of infection and pollution.

Below are few recommendations for the healthcare system of Brunei

- Focus on Sustainability of health care cost.
- Maintenance \& upgrade of existing health services \& facilities.

- Provision of new health services \& treatment modalities for emerging health requirements.

\section{References}

[1] Bloland, P., Simone, P., Burkholder, B., Slutsker, L., \& De Cock, K. M. The role of public health institutions in global health system strengthening efforts: the US CDC's perspective. PLoS medicine. 2012; 9(4):e1001199.

[2] Pakistan Economic Survey. Overview of the Economy. 2013-14. Available from http://www.finance.gov.pk/survey/chapters_13/exec utive\%20summary.pdf

[3] National Institute of Population Studies (NIPS) [Pakistan] and ICF International. Pakistan Demographic and Health Survey 2012-13. Islamabad, Pakistan, and Calverton, Maryland, USA: NIPS and ICF International; 2013

[4] Said, R. A Snapshot on Public Health Care Brunei Darussalam. 2012. Available from http://asiaincforum.com/documents/healthforum2012/Snapshot_of_Public_Health_Care.pdf

[5] Nishtar, S., Boerma, T., Amjad, S., Alam, A. Y., Khalid, F., Haq, I., \& Mirza, Y. A. Pakistan's health system: performance and prospects after the 18th Constitutional Amendment. The Lancet. 2013: 381(9884):2193-2206.

[6] World Health Organization. Country cooperation strategy for WHO and Pakistan 2011-2017; 2013

[7] National Health Policy 2009. Ministry of Health Government of Pakistan. 2009. Available from: http://www.ilo.org/wcmsp5/groups/public/--ed_protect/---protrav/---

ilo_aids/documents/legaldocument/wcms_117438.p df

[8] epikp. 2014. Retrieved from http://www.epikp.gov.pk/polio_updates.php

[9] Health Promotion Blueprint. Ministry of Health, Brunei Darussalam. 2011-2015. Available at http://www.moh.gov.bn/hpc/download/Annex\%204 $\% 20$ (Health\%20Promotion\%20 Blue print\%202011\%20-\%202015).

[10] Shaikh, S., Naeem, I., Nafees, A., Zahidie, A., Fatmi, Z., \& Kazi, A. Experience of devolution in district health system of Pakistan: Perspectives regarding needed reforms. JPMA-Journal of the Pakistan Medical Association. 2012; 62(1):28.

[11] Health Information Booklet. Ministry of Health, Brunei Darussalam. 2011. Available at http:// www.moh.gov.bn/satisticshealthguidelines/downloa d/HIB_2011.pdf

[12] Nishtar, S. The Gateway Paper; Health System in Pakistan - a Way Forward. Pakistan's Health Policy Forum and Heartfile; Islamabad, Pakistan. 2006. Available from http://www.heartfile.org/pdf/phpfGWP.pdf

[13] World Health organization report 2012. Health at a Glance Asia/Pacific (2012). 
Ministry of health of Brunei Darussalam

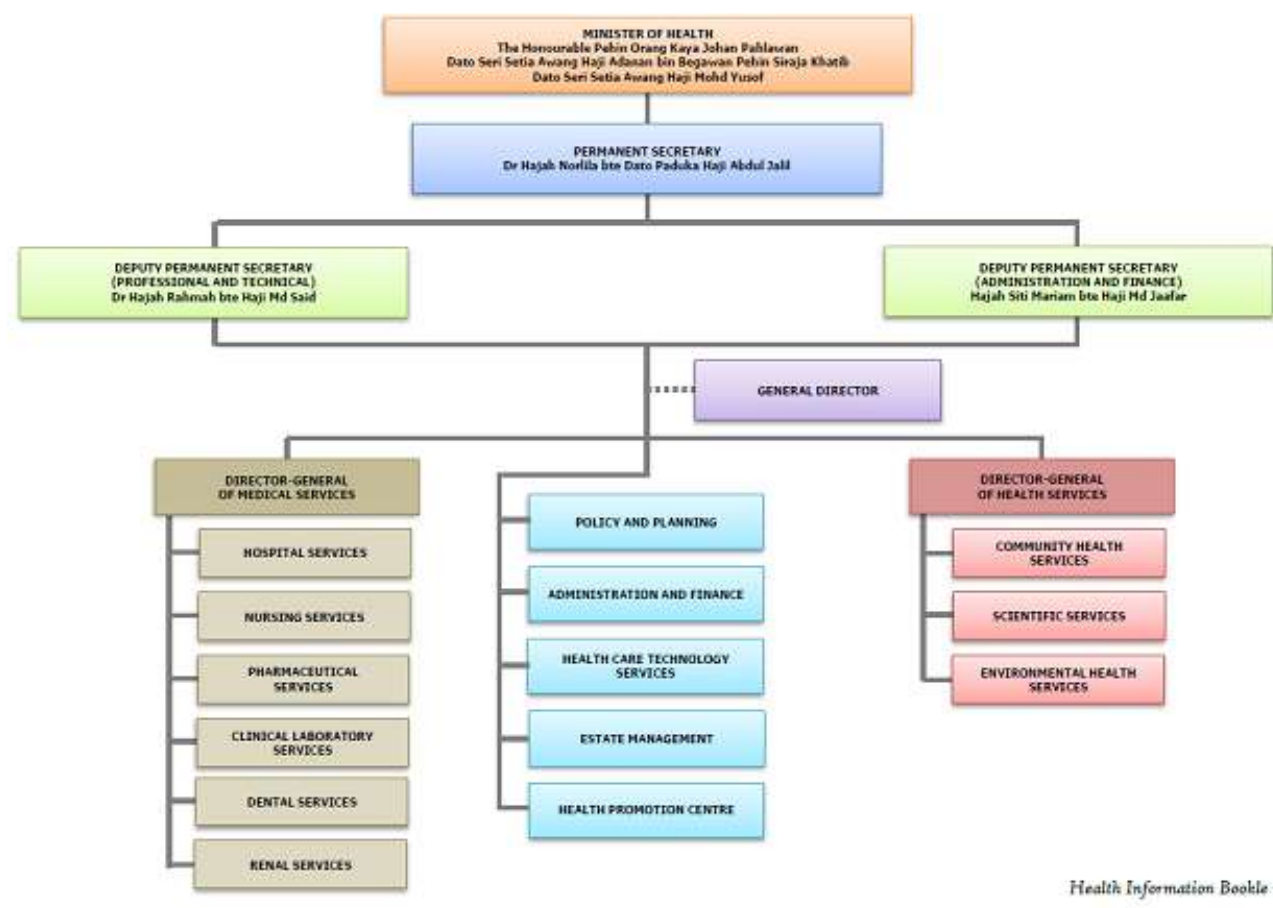

Volume 6 Issue 12, December 2017 www.ijsr.net 